Article

\title{
Assessment of LiDAR and Spectral Techniques for High-Resolution Mapping of Sporadic Permafrost on the Yukon-Kuskokwim Delta, Alaska
}

\author{
Matthew A. Whitley ${ }^{1, *}$, Gerald V. Frost ${ }^{2}$, M. Torre Jorgenson ${ }^{3}$, Matthew J. Macander ${ }^{2}$ (1), \\ Chris V. Maio ${ }^{1}$ and Samantha G. Winder ${ }^{4}$ \\ 1 Department of Geosciences, University of Alaska Fairbanks, Fairbanks, AK 99775, USA; \\ cvmaio@alaska.edu \\ 2 ABR, Inc.-Environmental Research \& Services, Fairbanks, AK 99709, USA; jfrost@abrinc.com (G.V.F.); \\ mmacander@abrinc.com (M.J.M.) \\ 3 Alaska Ecoscience, Fairbanks, AK 99709, USA; ecoscience@alaska.net \\ 4 Department of Statistics, University of Alaska Fairbanks, Fairbanks, AK 99775, USA; \\ sgwinder@alaska.edu \\ * Correspondence: mawhitley@alaska.edu; Tel.: +1-(804)-212-8542
}

Received: 24 October 2017; Accepted: 2 February 2018; Published: 7 February 2018

\begin{abstract}
Western Alaska's Yukon-Kuskokwim Delta (YKD) spans nearly 67,200 km² and is among the largest and most productive coastal wetland ecosystems in the pan-Arctic. Permafrost currently forms extensive elevated plateaus on abandoned floodplain deposits of the outer delta, but is vulnerable to disturbance from rising air temperatures, inland storm surges, and salt-kill of vegetation. As pan-Arctic air and ground temperatures rise, accurate baseline maps of permafrost extent are critical for a variety of applications including long-term monitoring, understanding the scale and pace of permafrost degradation processes, and estimating resultant greenhouse gas dynamics. This study assesses novel, high-resolution techniques to map permafrost distribution using LiDAR and IKONOS imagery, in tandem with field-based parameterization and validation. With LiDAR, use of a simple elevation threshold provided a permafrost map with $94.9 \%$ overall accuracy; this approach was possible due to the extremely flat coastal plain of the YKD. The addition of high spatial-resolution IKONOS satellite data yielded similar results, but did not increase model performance. The methods and the results of this study enhance high-resolution permafrost mapping efforts in tundra regions in general and deltaic landscapes in particular, and provide a baseline for remote monitoring of permafrost distribution on the YKD.
\end{abstract}

Keywords: LiDAR; permafrost mapping; Yukon-Kuskokwim Delta; Alaska; tundra

\section{Introduction}

Permafrost, or perennially frozen ground, is an important landscape feature for much of the Arctic and sub-Arctic regions of the world. An estimated $22-23 \%$ of land in the Northern Hemisphere, and $81 \%$ of Alaska, contains permafrost [1-3]. As global temperatures rise, landscapes underlain by permafrost are experiencing significant changes that have far reaching implications for geomorphology, hydrological processes, ecosystem services, and global carbon cycling [4-8].

Due to the widespread extent of permafrost around the globe, mapping at several scales is needed to fully understand permafrost landscapes [9]. With increasing air and ground temperatures across the Arctic, monitoring permafrost degradation (e.g., thermokarst) is important for understanding processes at both the local and the larger regional and global scales. Since nearly half of Alaska lies within the zones of isolated permafrost $(>0-10 \%$ permafrost landcover), sporadic permafrost $(10-50 \%)$, 
or discontinuous permafrost (50-90\%), large areas are at risk of being affected by permafrost thaw in the future [2]. This is especially true on the Yukon-Kuskokwim Delta (YKD), which is near the southern limit of permafrost in Alaska.

Prognostic models such as those from Pastick et al. [10] and Jafarov et al. [11] are in general agreement, projecting declines of $16-24 \%$ and $22 \%$, respectively in Alaskan near-surface permafrost extent by 2100 . These projections are also comparable to the 21-24\% reduction expected in Canada [12]. Even under moderate emissions scenarios, such as the Intergovernmental Panel on Climate Change's (IPCC) Representative Concentration Pathway (RCP) 4.5, permafrost is expected to retreat from the present-day discontinuous zone (including the YKD) by 2100 [13]. Under extreme scenarios modeled with RCP 8.5, sustainable permafrost will likely only be found in the Canadian Archipelago, Russian Arctic Coast, and east Siberian uplands by 2100 [13]. This projected retreat has implications for global carbon cycling, and underlines the critical need to advance techniques for mapping permafrost extent.

Mapping permafrost landscapes is inherently difficult, because permafrost itself is a thermal state of the subsurface, not a physical terrain [14]. However, proxies such as vegetation cover, regional air temperatures, topographic anomalies, and geomorphic landforms are useful for mapping permafrost extent [15]. Because many permafrost landscapes are logistically challenging to access, the use of remote sensing in permafrost analysis has increased dramatically in recent years $[15,16]$. Recent literature reviews provide useful overviews on the current state of permafrost remote sensing techniques [15-17].

Mapping permafrost extent usually incorporates some sort of process-based model to interpret where permafrost is present or absent. Such models are diverse in purpose, application, and complexity, but most of them rely on modeling ground thermal conditions using heat-transfer theory [9]. These methods model energy exchange among the atmosphere, snow, vegetation, active-layer soils, and permafrost. Though generally accurate in determining permafrost presence at regional to global scales, these models require many inputs that are only available at coarse spatial resolutions and are thus inadequate for distinguishing permafrost on spatially variable, discontinuous permafrost landscapes such as the YKD.

Here we present high spatial-resolution datasets suitable to the permafrost of the YKD: specifically, Light Detection And Ranging (LiDAR) and IKONOS satellite imagery. Repeat LiDAR has been shown to be useful in tracking thermokarst processes and landscape change in permafrost-rich areas [8,18-20], but to date there has not been an application of LiDAR to map permafrost extent explicitly. As previous studies overlook the YKD, the lack of a high-resolution permafrost map hinders landscape change analyses and the ability to assess the impacts of climate change to permafrost in this region of high biological productivity, critical wildlife habitats, and subsistence-based human economy.

The objectives of the study were to: (1) collect field data for parameterizing and validating the mapping algorithms; and (2) assess the viability of LiDAR and high spatial resolution spectral imagery (IKONOS) for mapping permafrost distribution on the YKD.

\section{Study Area}

The YKD of Alaska is one of the largest and most important coastal wetland regions in the pan-Arctic. Located in western Alaska, USA, the YKD provides nearly $67,200 \mathrm{~km}^{2}$ of habitat for migratory geese and waterbirds and is one of the most biologically productive areas of the arctic tundra biome [5,21]. YKD ecosystems help sustain one of the largest indigenous human populations in the Arctic. Living in 56 villages, roughly 23,000 Yup'ik and Cup'ik people rely heavily on subsistence resources [22,23]. As temperatures and sea levels rise in the Arctic, uncertainty in the stability of coastlines and permafrost may drive landscape change on a region-wide scale, affecting the livelihoods of local communities as well as the habitats of several species of conservation concern [24].

This study focuses on the western portion of the YKD between the village of Chevak and Hazen Bay (Figure 1). This region of the YKD is extremely flat; previous elevation profiles have shown topographic gradients of as little as $0.5 \mathrm{~m}$ over $7.5 \mathrm{~km}$ distance [24]. The flat topography makes the 
YKD highly vulnerable to eustatic sea-level rise and inland storm surges, which have been known to flood up to $37 \mathrm{~km}$ inland [25].

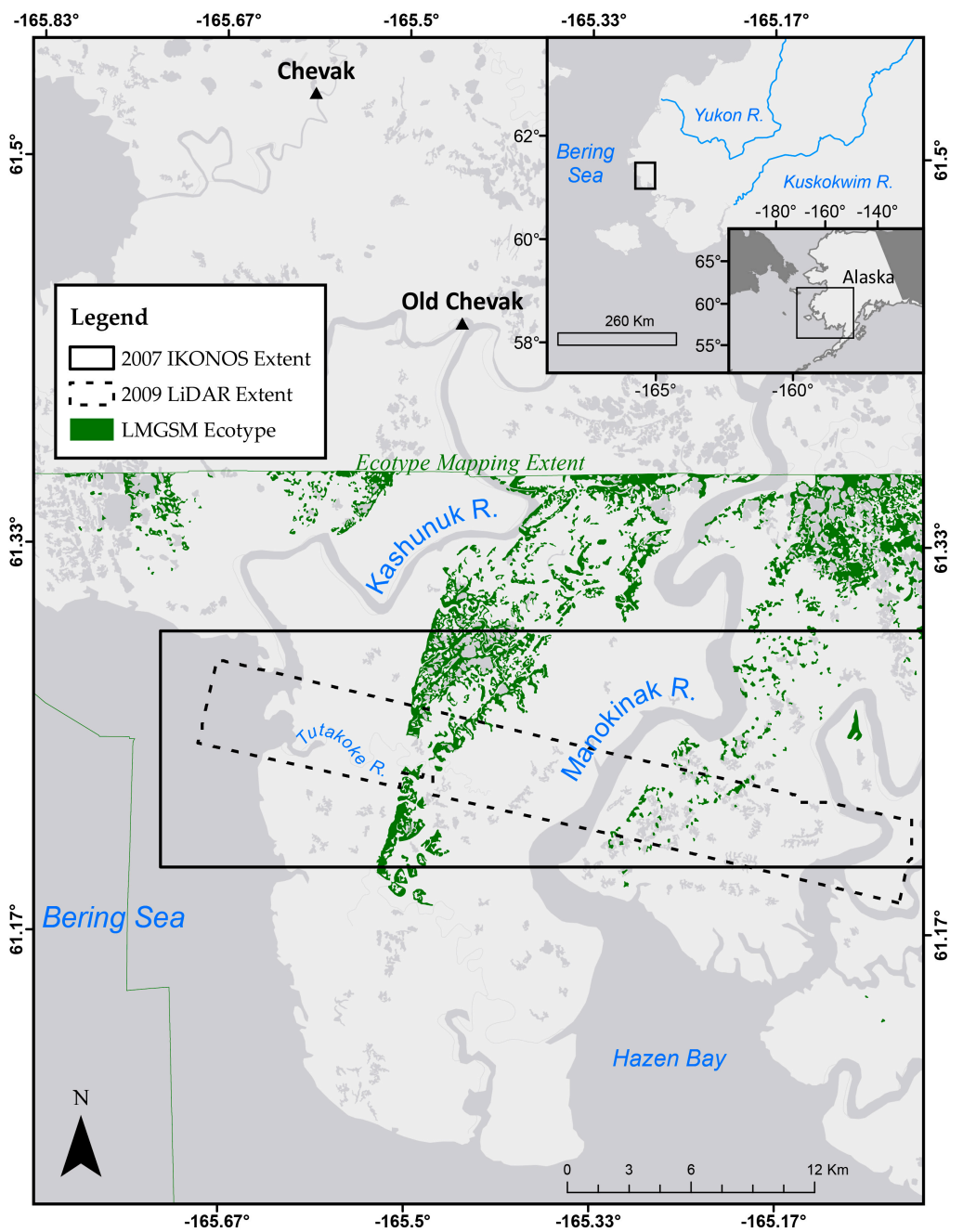

Figure 1. Study Area located on the Yukon-Kuskokwim Delta (YKD) in western Alaska, USA. Depicted are the extent of the 2007 IKONOS data (solid line), the extent of the 2009 LiDAR data (dashed line), and the approximate distribution of the Lowland Moist Graminoid Shrub Meadow (LMGSM) ecotype (green) that is associated with permafrost plateaus [5].

This landscape is at the southern extent of permafrost in Alaska, and lies in the sporadic to isolated permafrost zone [2]. The mean annual air temperature (MAAT) $200 \mathrm{~km}$ east of the study area at Bethel, AK is $-1.2^{\circ} \mathrm{C}$ (1923-present), making the region warm for supporting permafrost [26,27]. The instrumental record at Bethel shows a warming trend that will likely result in MAAT above $0{ }^{\circ} \mathrm{C}$ in the future (Figure 2). Under these climatic conditions, the permafrost is considered ecosystem-protected permafrost, meaning the insulative cover of vegetation and organic matter is critical for permafrost stability under otherwise incompatible air temperatures and is unlikely to re-form after disturbance [28].

Permafrost occurrence in the study area is tied to the gradual elevation ramp from the coast inland; the landscape progresses from coastal mudflats to active floodplains (flood frequently), then to inactive floodplains (flood occasionally), and finally to abandoned floodplains (rarely flood) [29]. Permafrost in the area is restricted to abandoned floodplains, as interactions from storms and tides prohibit permafrost formation closer to the coast $[24,25]$. Permafrost manifests as plateaus on the landscape, because segregated ice in the soil raises the ground surface 1-2 m relative to younger floodplain deposits [24]. Previous work estimates permafrost thickness of roughly 10-m based on plateau height, with poorly developed 
cryostructures limited to pore ice and lenticular ice [24,29]. Because of this elevation difference, permafrost plateaus have better drainage and support vegetation that is less tolerant to saltwater inundation such as dwarf shrubs (e.g., Betula nana, Rhododendron subarcticum, Empetrum nigrum, Salix fuscescens), mosses (e.g., Sphagnum, Dicranum), and lichens (e.g., Cladonia, Cladina) [5,24]. The lichen- and moss-rich vegetation has insulative properties conducive to formation and protection of permafrost, where low thermal conductivity in the summer insulates underlying permafrost from warmer air temperatures, but higher thermal conductivity in the winter allows for heat loss from the ground [30]. The surrounding lowlands are mostly sedge meadows dominated by hydrophytic species such as Carex aquatilis, C. rariflora, C. lyngbyei, Eriophorum scheuchzeri, and Comarum palustre; these species can be locally common on degrading permafrost and are bioindicators of recent thermokarst (Figure 3).

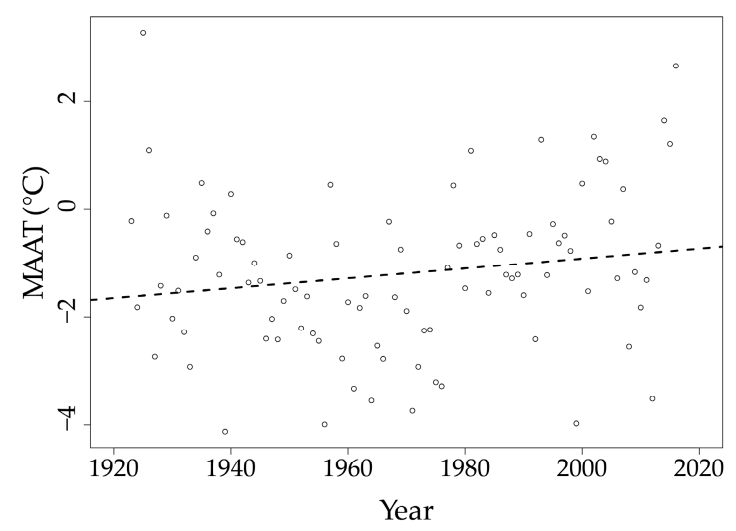

Figure 2. Temperature trend for Bethel, Alaska (200 km east of study area). Linear regression shows a warming trend of Mean Annual Air Temperatures (MAAT): $\hat{\beta}_{1}=0.009(p=0.0941)$, Adjusted $\mathrm{R}^{2}=0.020$.

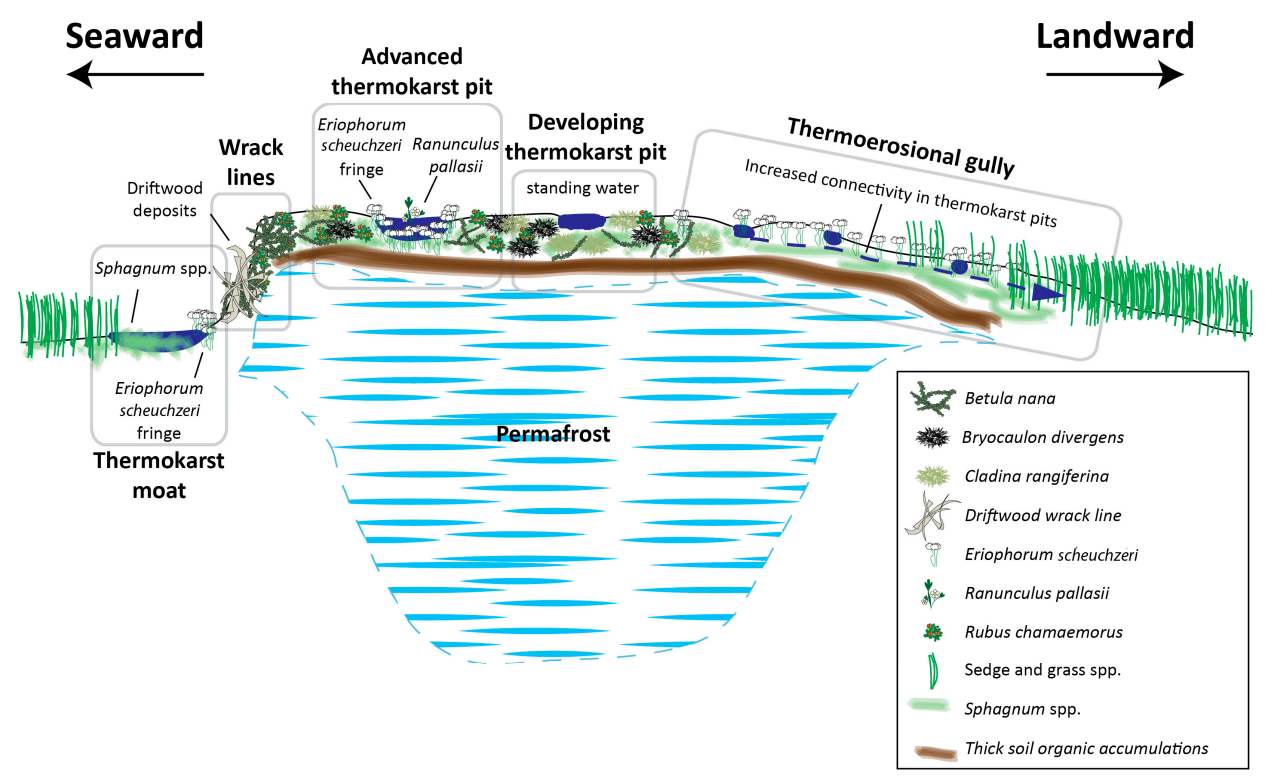

Figure 3. Conceptual model of permafrost plateau morphology, vegetation, permafrost thickness, and thermokarst processes. The Lowland Moist Graminoid Shrub meadow (LMGSM) ecotype is associated with the permafrost plateaus, which are surrounded by other, wetter coastal meadow ecotypes. There is typically an abrupt transition from coastal meadow to plateau on the seaward margin, and a gradual transition between ecotypes on the landward margin. Thick organic accumulations on the permafrost plateaus help to insulate underlying permafrost during summer. Indicators of various stages of permafrost degradation are highlighted with grey boxes. 


\section{Materials and Methods}

\subsection{Fieldwork}

Field data were collected 8-17 July 2016 to support mapping analysis and validation. Transects running perpendicular to the boundary of permafrost plateaus were established subjectively according to topographic breaks, vegetation, presence of storm indicators (e.g., driftwood), and evidence of thermokarst (e.g., thermokarst pits, moats, thermo-erosional gullies). Nine transects were sampled, with transect lengths ranging from 50 to $130 \mathrm{~m}$ (Figure 1). Thaw depths were measured along each transect every $1 \mathrm{~m}$ over permafrost and $5 \mathrm{~m}$ over non-permafrost using a $1.25 \mathrm{~m}$ thaw probe and a Delorme PN-60 GPS ( $\pm 5 \mathrm{~m}$ horizontal accuracy) (Figure 4). In addition to frost presence/absence, the dominant plant species were recorded, and each sample point was assigned to an ecotype [5,29]. When possible, the thickness of seasonal frost and/or permafrost was measured by breaking through frozen ground along the plateau margins. Since sampling was conducted in mid-July, seasonal frost was likely encountered in addition to the permafrost along these margins. However, the relative elevations and distinctive vegetation create a clear binomial characterization of permafrost presence/absence on the plateaus. These transects helped describe the boundary conditions between permafrost plateaus and the surrounding floodplain deposits, which were useful for both parameterization and validation of the permafrost mapping. For validation, 333 GPS points and thaw-depth measurements were collected opportunistically along the coast-inland gradient, separate from those collected along the transects. These validation points were later categorized as binary permafrost/non-permafrost for use in validating the map products.

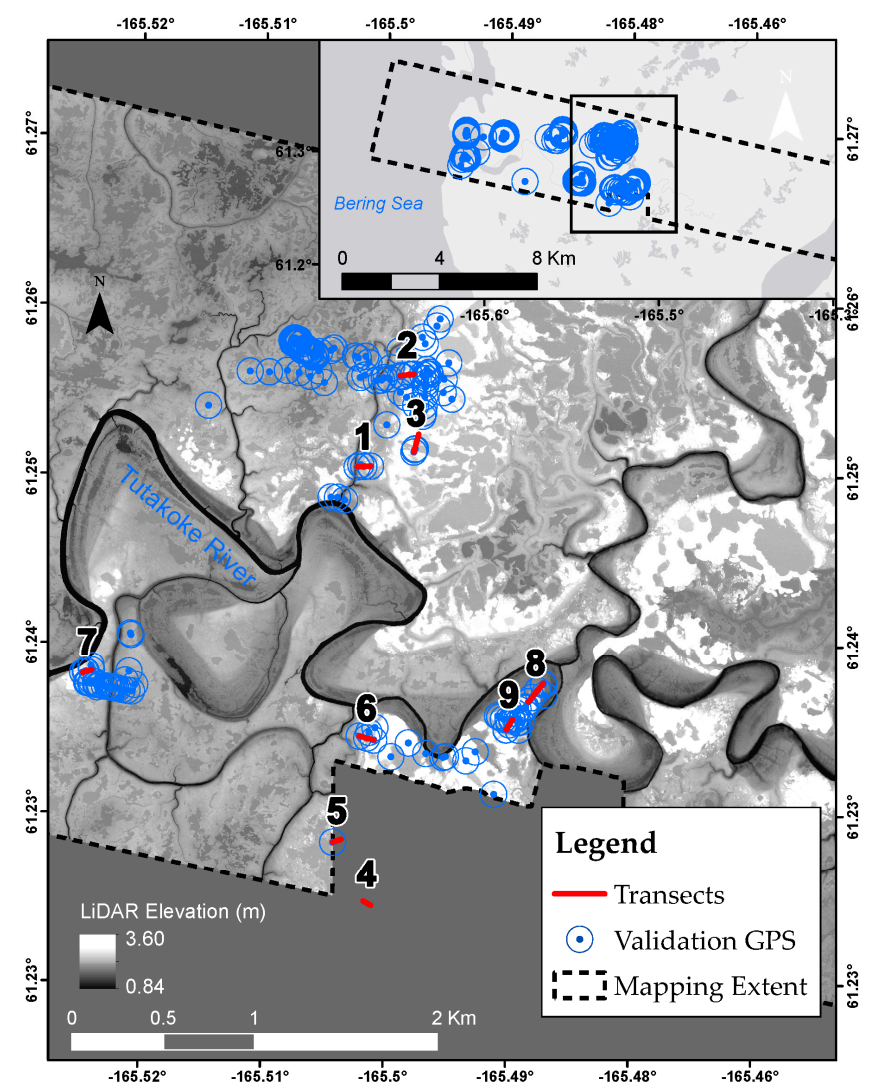

Figure 4. Locations of transects, field validation sampling points, and the mapping extent (dashed line) near the Tutakoke River, YKD. The thaw-depth transects (bold numbers) are shown in red, and the field validation points are shown in blue. 
The transect data were then analyzed by ecotype and elevation. Similar ecotypes were grouped together to ensure a minimum sample size of at least 10 observations per ecotype. The ecotypes analyzed included: Lowland Moist Graminoid Shrub Meadow (LMGSM), Lowland Wet Graminoid Shrub Meadow (LWGSM), Lowland Wet Sedge Meadow (LWSM), Lowland Wet Sedge-Shrub Meadow (LWSSM), Riverine Moist Graminoid Shrub Meadow (RMGSM), Thermokarst Pits (TP), Water (W), and Wrack Lines (WL) from previous storm surges. The W class encompassed channels, lakes, and ponds created by deltaic processes, and the TP class encompassed small ponds on top of the permafrost plateaus created from permafrost degradation. The average elevation and the percentage of sample points with permafrost were then calculated for each ecotype. Locations probed where frost was encountered were also tested for differences in percent frozen ground by ecotype with an Analysis of Variance (ANOVA) and a Dunnett-modified Tukey-Kramer (DTK) test [31]. Elevations above mean sea level (a.m.s.l.) were similarly analyzed by ecotype.

\subsection{LiDAR Mapping}

A LiDAR mission flown between 27 June and 2 July 2009 by Kodiak Mapping, Inc. (Palmer, AK, USA) was the base dataset used for this mapping [32]. When processing the LiDAR data, only the last returns were considered to create a DEM with $1 \mathrm{~m}$ horizontal resolution and $0.05 \mathrm{~m}$ vertical resolution.

The DEM was subsequently adjusted to elevation a.m.s.l. with a three step process that: (1) determined the mean sea level for the area based on an in situ tide gauge; (2) compared the water level with ground control networks from 1997 and 2010; and (3) calculated the offset for the 2009 LiDAR DEM. Mean sea level was calculated from a HOBO Data Logger tide gauge (Onset Computer Corporation; Bourne, MA, USA) deployed from 28 July 2009 to 30 November 2010. The tide gauge was found to be consistent with most of the 2010 ground control information, but was ultimately tied to the 1997 control network for consistency with 15 years of previous analyses and publications [24,29]. The tide-corrected LiDAR elevations were $0.98 \mathrm{~m}$ lower than the NGVD88 vertical datum based on the GEOID96 model in which the LiDAR data were originally processed.

Using the corrected LiDAR dataset, elevations of the permafrost plateau margins were extracted at the points sampled along the transects in the field. This was performed through photo-interpretation of the transitions from permafrost plateau to coastal meadows using high-resolution imagery. To map permafrost extent in the LiDAR swath, a threshold was selected based upon mean elevation of the boundaries +1 standard deviation (SD). Other thresholds were considered, but were discarded after visual interpretation of preliminary results. This threshold was then used to create a binary mask of areas with permafrost (elevations above the threshold) and areas without permafrost (elevations below the threshold). This map was subsequently validated using the 333 GPS points collected in the field that fell within the LiDAR swath (Figure 4).

The relationship between elevation and permafrost occurrence was also analyzed using logistic regression by assessing whether or not permafrost was encountered at each thaw-depth sample point along the transects (not just those on the boundaries of the plateaus). Elevations were extracted from the LiDAR DEM at each thaw-depth sample point and modeled against the presence or absence of permafrost at each point. The resulting model was used to predict the probability of permafrost occurrence in $0.1 \mathrm{~m}$ elevation bins that spanned all observed elevations. This resulted in a permafrost probability map that quantifies the uncertainty of whether or not permafrost is present.

Finally, the LiDAR workflow was validated using the 333 field observations. Confusion matrices were calculated for each mapping threshold in order to quantify mapping accuracies for each threshold [33]. The producer's accuracy in the confusion matrix is defined as the number of observations mapped correctly divided by the total number of field observations in that class, and is the converse of the error of omission. The user's accuracy is defined as the number of observations mapped correctly divided by the total number of observations mapped as that class, and is the converse of the error of commission. $\hat{k}$, a statistic that describes how well the model performed in relation to what would be expected by chance, was also calculated for each map. 


\subsection{Spectral Integration}

To augment the LiDAR analysis, an IKONOS image from 27 August 2007 was incorporated with the LiDAR data into a Random Trees (RT) classifier. The raw IKONOS Digital Numbers (DNs) were resampled to match the $1 \mathrm{~m}$ LiDAR grid and orientation using a nearest-neighbor resampling technique. The multispectral IKONOS bands (red, green, blue, and near infrared) were then stacked with the LiDAR data as input into the RT classification. The RT classifier available in the ArcGIS software suite [34] is similar to a Random Forest classification method [35], and creates a series of decision trees based upon random subsets of variables, and classifies the image based on the most frequent tree output. To compare to the LiDAR methods, the RT classification was trained using the thaw-depth sample points along the transects, which were buffered by $0.5 \mathrm{~m}$ to satisfy the geometry requirements of the ArcGIS tool. The RT algorithm was capped at the default 50 trees, with each having a maximum depth of 30 decisions. A separate RT classification was also conducted using the IKONOS and LiDAR data, but was trained using manually delineated polygons that expanded the training beyond the inactive and abandoned floodplain deposits, and incorporated a water class (which was not considered permafrost for validation purposes). These training polygons, selected through photo-interpretation of the 2007 IKONOS scene, encompassed homogenous areas of water, permafrost, and non-permafrost sampled across the coast-inland gradient. The second RT classification also used the default tree number and depth. The integrated classification methods were both validated using the 333 GPS points collected in the field.

\section{Results}

\subsection{Transect Profiles}

A total of 493 thaw depths were measured over $677 \mathrm{~m}$ of transect running across the permafrost plateau margins. In all, 29 distinct transitions from permafrost plateau to coastal meadow were observed along the transects, 27 of which were within the LiDAR swath. The average elevation of these boundaries extracted from the LiDAR DEM was $2.3 \mathrm{~m}$ a.m.s.l., with a SD of $0.2 \mathrm{~m}$. Minimum and maximum boundary elevations were $2.0 \mathrm{~m}$ and $2.8 \mathrm{~m}$ a.m.s.l., respectively.

Frozen ground was encountered at $68.9 \%$ of the sample sites (not adjusting for potential seasonal frost) (Table 1). When analyzed by ecotype, permafrost was rarely encountered in the RMGSM, LWSSM, and LWGSM ecotypes; and no permafrost was encountered in the Water class (Figure 5). An ANOVA revealed that there were significant differences in mean thaw depths among the various ecotypes $(\alpha=0.05 ; d f=6, n=333 ; \mathrm{F}=33.36 ; p \leq 0.0001)$. The subsequent pairwise DTK test found that the LWSM was statistically different from the LWGSM, the RMGSM, and the TP at a 95\% confidence level.

The mean elevation at sample points within the LiDAR swath was $2.43 \mathrm{~m}$ a.m.s.l. These elevations were also analyzed by ecotype (Figure 6). The ANOVA conducted on elevations also found significant differences among ecotypes $(\alpha=0.05 ; d f=7, n=424 ; \mathrm{F}=23.99 ; p \leq 0.0001)$. The subsequent DTK test found the LMGSM statistically different from every other ecotype except the TP and the WL; the RMGSM statistically different from the TP, the LWSSM, and the LWGSM; and the TP statistically different from the LWSM, the RMGSM, and the LWGSM.

Table 1. Percent of sample sites with frozen ground by ecotype.

\begin{tabular}{cccc}
\hline Ecotype & Acronym & $\boldsymbol{n}$ & Percent Frozen Ground \\
\hline Water & W & 7 & $0.0 \%$ \\
Lowland Wet Graminoid Sedge Meadow & LWGSM & 35 & $5.7 \%$ \\
Lowland Wet Sedge-Shrub Meadow & LWSSM & 60 & $10.0 \%$ \\
Riverine Moist Graminoid Shrub Meadow & RMGSM & 23 & $21.7 \%$ \\
Lowland Wet Sedge Meadow & LWSM & 40 & $40.0 \%$ \\
Thermokarst Pit & TP & 21 & $85.7 \%$ \\
Lowland Moist Graminoid Shrub Meadow & LMGSM & 292 & $94.9 \%$ \\
Wrack Line & WL & 15 & $100.0 \%$ \\
Total & & 493 & $68.9 \%$ \\
\hline
\end{tabular}




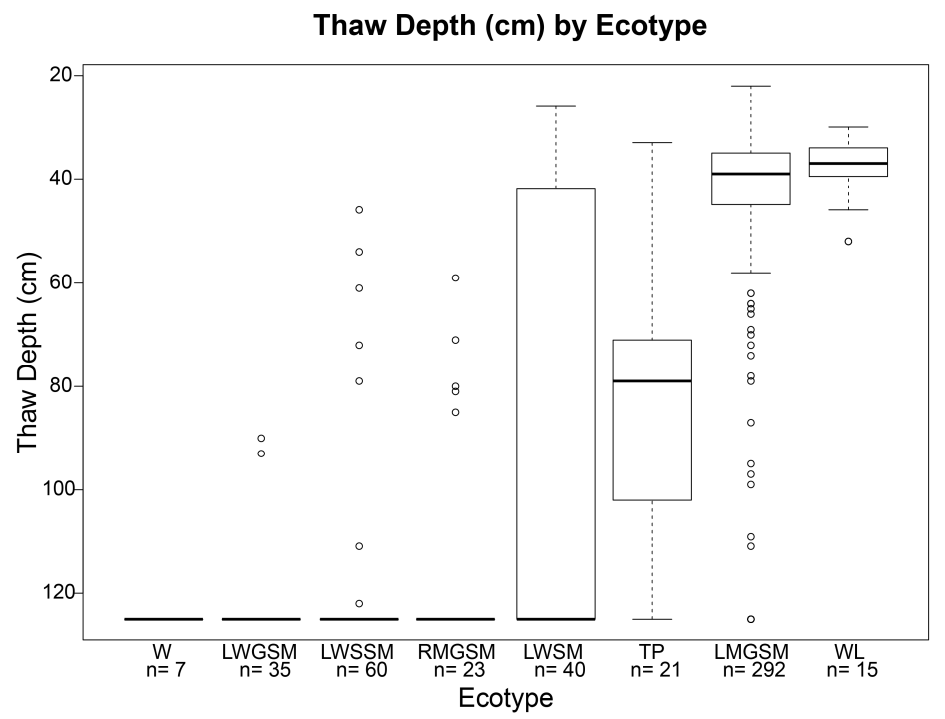

Figure 5. Thaw depth by ecotype. Bold horizontal lines show the median thaw depth for each transect, the boxes show the Inter-Quartile Range (IQR), and the whiskers show $1.5 \times \mathrm{IQR} \pm 1$ st and 3rd quartiles, respectively. Circles beyond the whiskers indicate outliers. Note that the maximum thaw depth was the length of the thaw probe and depths of $125 \mathrm{~cm}$ indicates a lack of permafrost in most cases.

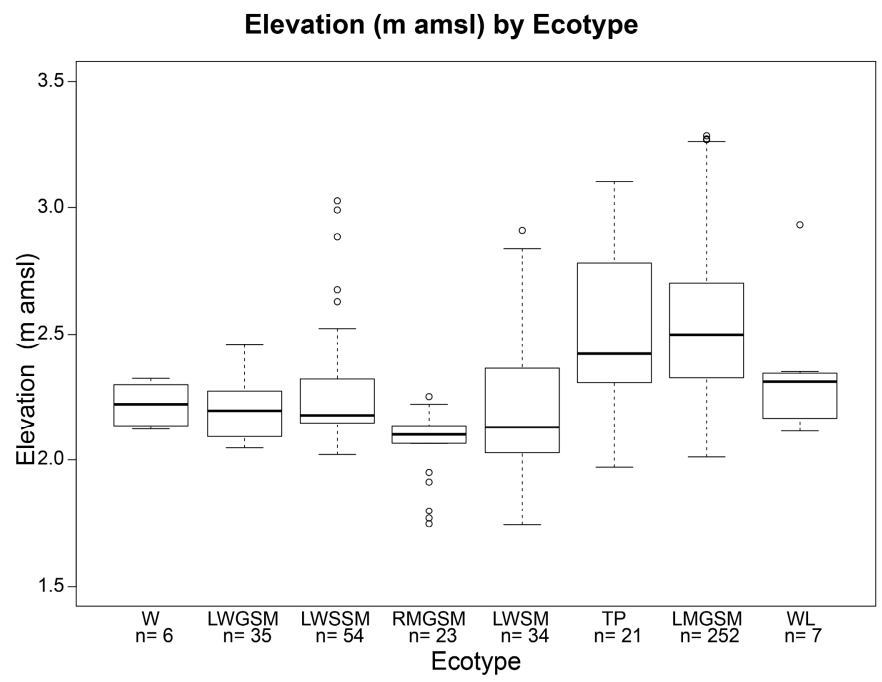

Figure 6. Elevation ( $\mathrm{m}$ above mean sea level) of sample sites along field transects by ecotype. Bold horizontal lines show the median thaw depth for each transect, the boxes show the IQR of the thaw data, and the whiskers show $1.5 \times \mathrm{IQR} \pm 1$ st and 3rd quartiles, respectively. Circles beyond the whiskers indicate outliers.

Frost thickness measurements (bottom of frost depth-top of frost depth) were collected for 19 of the sample points $(3.9 \%)$, which all occurred along the permafrost margins, where frozen ground was thin enough to break through while probing. The average thickness of frozen ground at these points was $26.1 \mathrm{~cm}(15.7 \mathrm{~cm} \mathrm{SD})$, with a maximum thickness of $62.0 \mathrm{~cm}$ and a minimum thickness of $3.0 \mathrm{~cm}$. The average depth at the bottom of these frost measurements was $86.6 \mathrm{~cm}$.

Further probing found that permafrost was still present under most shallow ponds and thermokarst pits on the plateaus (85.7\% permafrost occurrence), including those with substantial cover of recently established wetland plants indicative of advanced stages of thermokarst. Areas with driftwood and storm wrack along the margins of the plateaus were generally underlain by permafrost as well. In general, frost depth and vegetation varied predictably by ecotype and elevation (Figure 7). 

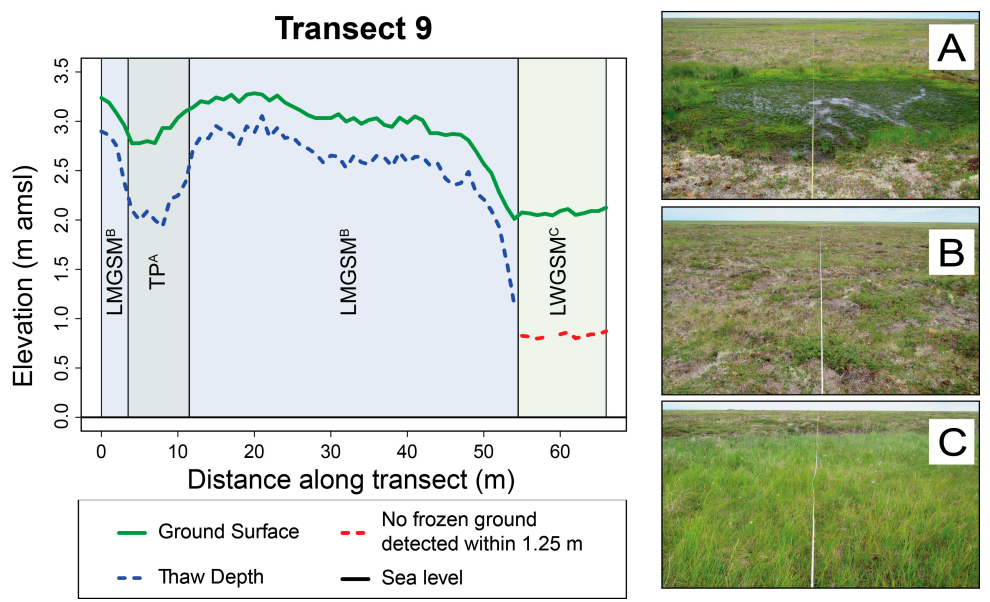

Figure 7. Elevation profile of transect 9 depicting observed ecotypes: (A) Thaw Pit (TP); (B) Lowland Moist Graminoid Shrub Meadow (LMGSM); and (C) Lowland Wet Graminoid-Shrub Meadow (LWGSM); surface elevation (solid green line); top of frost (dashed blue line); and areas where no frost was encountered in the top $1.25 \mathrm{~m}$ (dashed red line).

\subsection{LiDAR Mapping}

Several thresholds for the LiDAR mapping method were explored, but the threshold yielding the highest mapping accuracy was $2.5 \mathrm{~m}$ a.m.s.l. (mean $+1 \mathrm{SD}$ ) (Figure 8). Validation from the 333 GPS points within the LiDAR swath showed that the resultant LiDAR map achieved $94.9 \%$ total accuracy in mapping permafrost occurrence (Table 2). The model was $98.9 \%$ accurate in mapping areas without permafrost, but only $80.3 \%$ accurate in mapping areas with permafrost. The map had $84 \%$ better agreement than would be expected by chance alone $(\hat{k}=0.84)$.

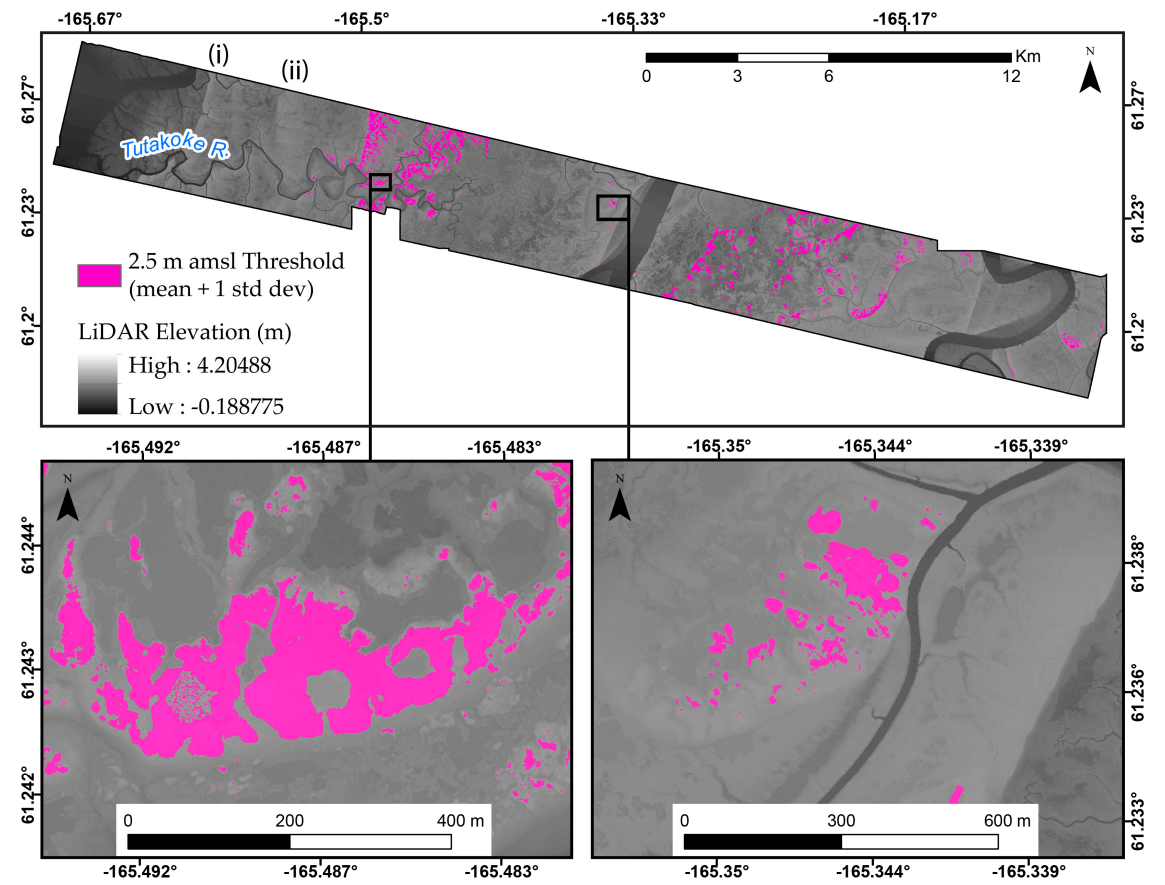

Figure 8. High-resolution map of permafrost distribution created using the $2.5 \mathrm{~m}$ a.m.s.l. (mean $+1 \mathrm{SD}$ ) threshold for the entire 2009 LiDAR swath. The insets show more detail in areas of relative high elevation (left) and areas of relative low elevation (right). Transitions between the mudflat and active floodplain deposit (i), and active and inactive floodplain deposits (ii) are also shown. 
Table 2. LiDAR model accuracy for mapping permafrost using the $2.5 \mathrm{~m}$ a.m.s.l. (mean $+1 \mathrm{SD}$ ) threshold. Producer's accuracy is defined as the number of correctly mapped observations in a class (bolded) divided by the total number of field observations in that class (column total). User's accuracy is defined as the number of correctly mapped observations in a class divided by the total number of observations mapped as that class (row total). Overall accuracy is defined as the sum of correctly classified observations divided by the total number of observations.

\begin{tabular}{cccccc}
\hline \multicolumn{5}{c}{ Field Data } \\
\hline \multirow{6}{*}{ Mapped } & Absent & Present & Row Total & User's Accuracy \\
\cline { 3 - 6 } & Absent & $\mathbf{2 5 9}$ & 14 & 273 & $94.9 \%$ \\
& Present & 3 & $\mathbf{5 7}$ & 60 & $95.0 \%$ \\
& Column Total & 262 & 71 & 333 & - \\
& Producer's accuracy & $98.9 \%$ & $80.3 \%$ & - & - \\
& Overall Accuracy & - & - & - & $94.9 \%$ \\
\hline
\end{tabular}

The logistic regression found that elevation was a highly significant indicator of near-surface permafrost in the region $(z=9.056, p \leq 0.0001)$, such that there was a higher likelihood of encountering near-surface permafrost at high elevations, and lower likelihood of encountering near-surface permafrost at low elevations. Predicted probability of occurrence was high at elevations greater than $2.5 \mathrm{~m}$ a.m.s.l., and low at elevations less than $2 \mathrm{~m}$ a.m.s.l. Areas between 2 and $2.5 \mathrm{~m}$ a.m.s.l. had a mix of permafrost and non-permafrost, resulting in probabilities of occurrence $\sim 0.5$. These uncertainties and probabilities are apparent in a logistic regression (Figure 9), as well as spatially when the probabilities are mapped from the 2009 LiDAR swath (Figure 10). When a 0.90 probability ( $2.55 \mathrm{~m}$ a.m.s.l.) was selected as a threshold for mapping, the binary map (permafrost/non-permafrost) produced showed slightly lower accuracy but was still comparable to the $2.5 \mathrm{~m}$ a.m.s.l. (mean $+1 \mathrm{SD}$ ) threshold (Table 3).

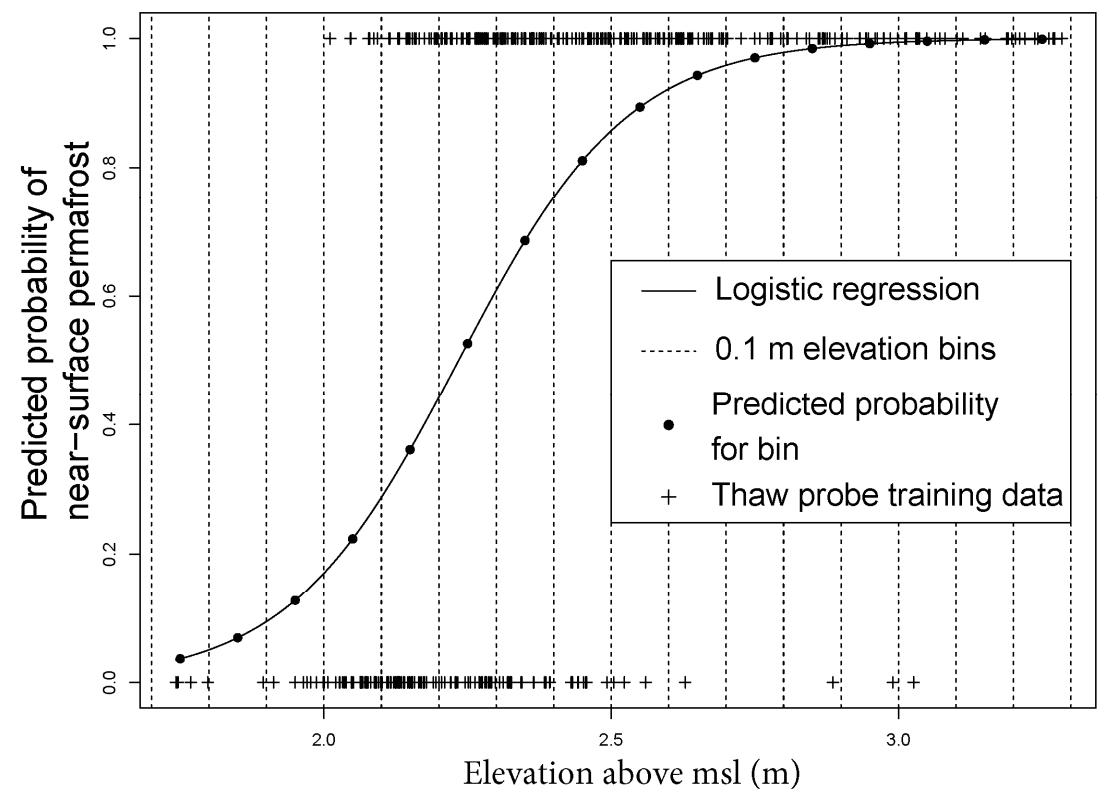

Figure 9. Probability of near-surface permafrost as predicted by $0.1 \mathrm{~m}$ elevation bins. The plus signs show permafrost observations ( 1 = permafrost, $0=$ non-permafrost $)$ plotted by elevation; permafrost only occurs at the top of the plot (probability =1), and absence of permafrost only occurs at the bottom (probability $=0$ ) because of the binomial nature of sampling. 


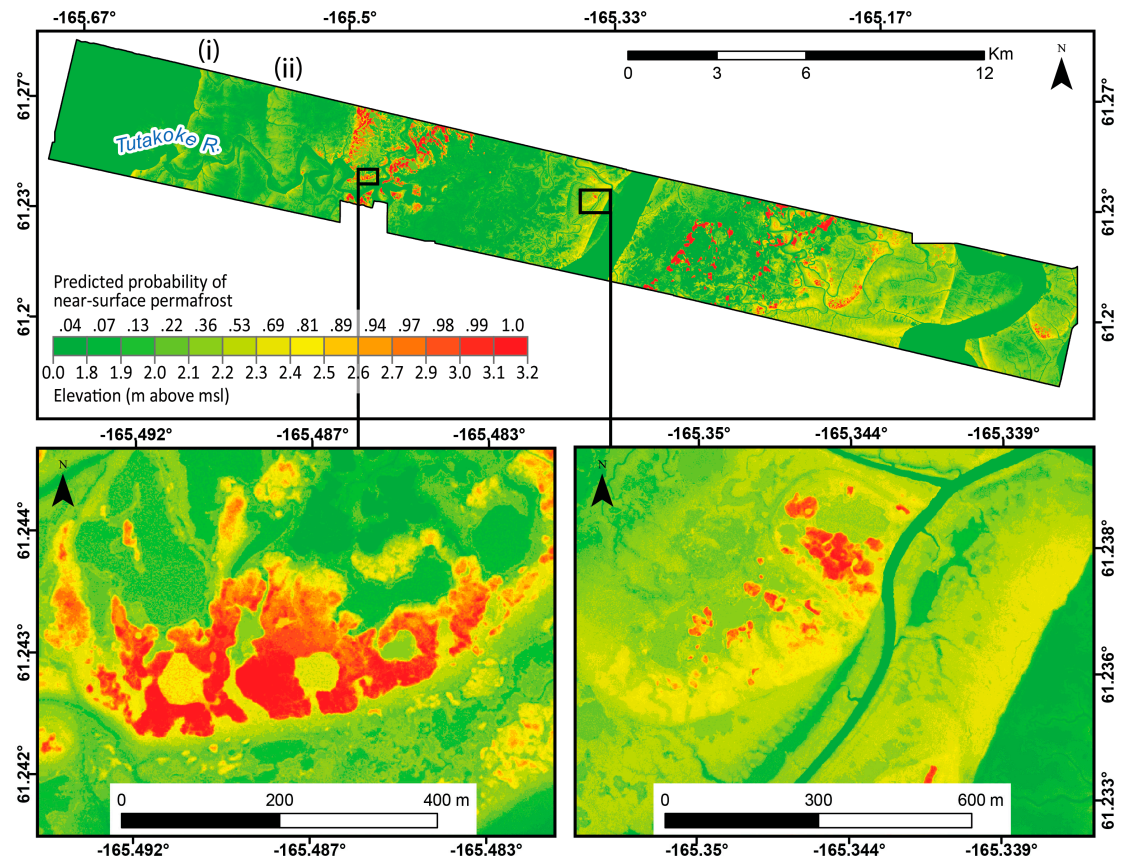

Figure 10. Map of the predicted near-surface permafrost probability calculated by $0.1 \mathrm{~m}$ elevation bins for the entire 2009 LiDAR swath. The insets show more detail in areas of relative high elevation (left) and areas of relative low elevation (right). Transitions between the mudflat and active floodplain deposit (i), and active and inactive floodplain deposits (ii) are also shown.

Table 3. LiDAR model accuracy based upon 333 GPS points taken in the field for a 0.9 predicted probability threshold.

\begin{tabular}{cccccc}
\hline \multicolumn{6}{c}{ Field Data } \\
\hline \multirow{7}{*}{ Mapped } & & Absent & Present & Row Total & User's Accuracy \\
& Absent & $\mathbf{2 5 9}$ & 15 & 274 & $94.5 \%$ \\
& Present & 3 & $\mathbf{5 6}$ & 59 & $94.9 \%$ \\
& Column Total & 262 & 71 & 333 & - \\
& Producer's accuracy & $98.9 \%$ & $78.9 \%$ & - & - \\
& Overall Accuracy & - & - & - & $94.6 \%$ \\
\hline
\end{tabular}

\subsection{Spectral Integration}

When the IKONOS imagery was integrated with the LiDAR data in a RT classification using the same training and validation as the logistic regression, overall accuracy of the resultant permafrost map dropped to $89.5 \%$, with only a $73 \%$ better agreement than would be expected by chance alone $(\hat{k}=0.73)($ Table 4$)$.

Table 4. Model accuracy of integrated Regression Tree (RT) classification trained with thaw-depth sample points along transects (same training as logistic regression).

\begin{tabular}{lccccc}
\hline \multicolumn{5}{c}{ Field Data } \\
\hline \multirow{2}{*}{ Mapped } & Absent & Present & Row Total & User's Accuracy \\
\cline { 3 - 6 } & Absent & $\mathbf{2 2 9}$ & 2 & 274 & $99.1 \%$ \\
& Present & 33 & $\mathbf{6 9}$ & 59 & $67.6 \%$ \\
& Column Total & 262 & 71 & 333 & - \\
& Producer's accuracy & $87.4 \%$ & $97.2 \%$ & - & - \\
& Overall Accuracy & - & - & - & $89.5 \%$ \\
\hline
\end{tabular}

However, when the RT classification was trained using a more extensive training set created from visual interpretation of the landscape, the model resulted in a $94.3 \%$ overall accuracy, with a $82 \%$ better 
agreement than would be expected by chance alone $(\hat{k}=0.82)$ (Table 5$)$. The second RT classification resulted in a landcover map with cleaner boundaries and classes compared to the first RT classification (Figures 11 and 12).

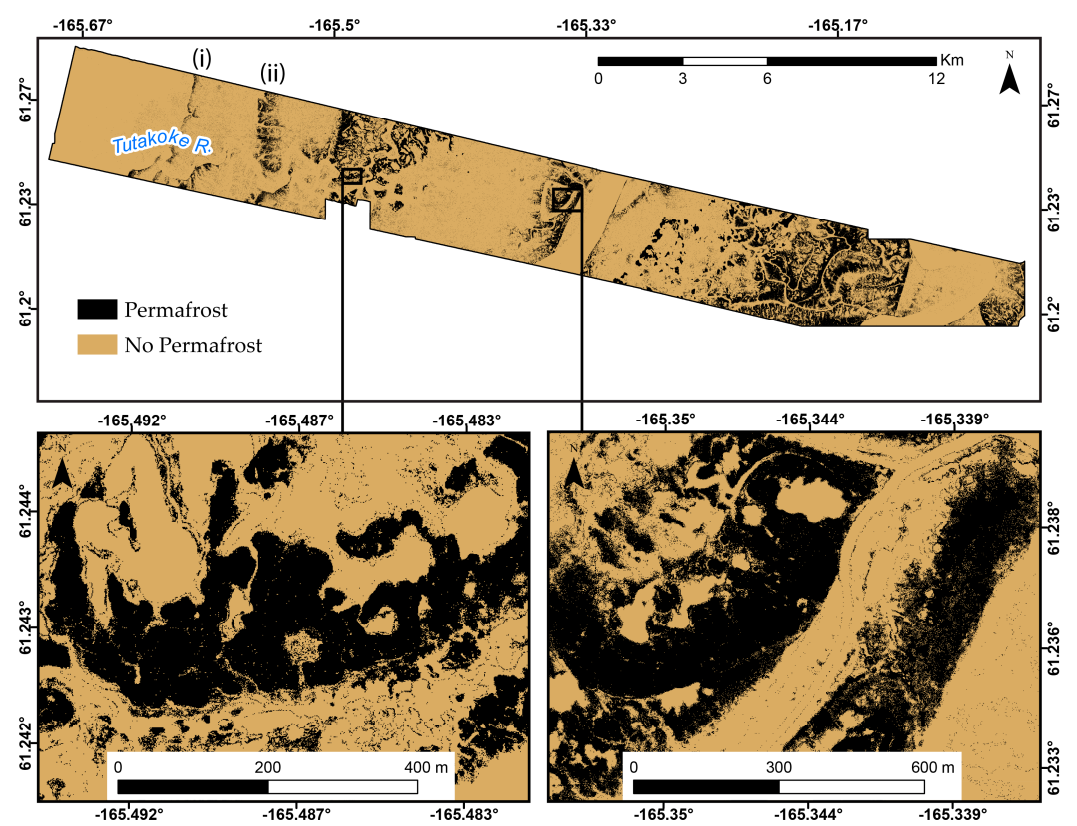

Figure 11. Permafrost map from the integrated RT classification trained with thaw-depth sample points along transects (same training as logistic regression). The insets show more detail in areas of relative high elevation (left) and areas of relative low elevation (right). Transitions between the mudflat and active floodplain deposit (i), and active and inactive floodplain deposits (ii) are also shown.

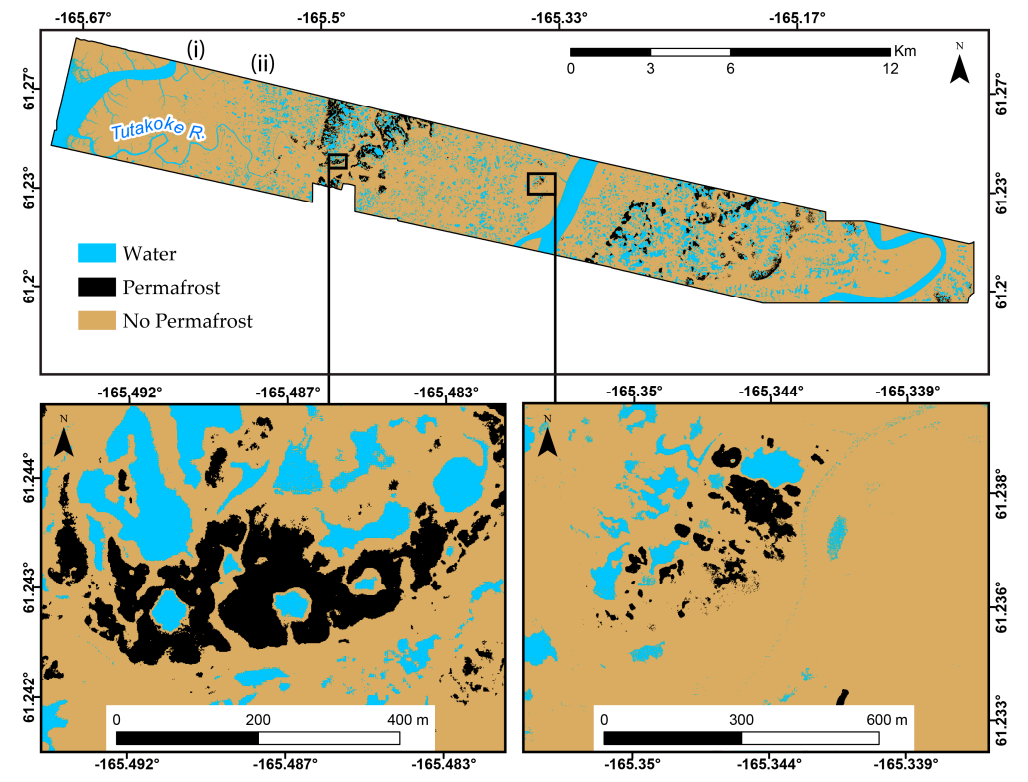

Figure 12. Permafrost map from the integrated RT classification trained with visual interpretation of the landscape (larger training set than the logistic regression). The insets show more detail in areas of relative high elevation (left) and areas of relative low elevation (right). Transitions between the mudflat and active floodplain deposit (i), and active and inactive floodplain deposits (ii) are also shown. 
Table 5. Model accuracy of integrated RT classification trained with visual interpretation of the landscape (larger training set than the logistic regression).

\begin{tabular}{cccccc}
\hline \multicolumn{5}{c}{ Field Data } \\
\hline \multirow{6}{*}{ Mapped } & Absent & Present & Row Total & User's Accuracy \\
& Absent & $\mathbf{2 5 8}$ & 15 & 274 & $94.5 \%$ \\
& Present & 4 & $\mathbf{5 6}$ & 59 & $93.3 \%$ \\
& Column Total & 262 & 71 & 333 & - \\
& Producer's accuracy & $98.5 \%$ & $79.8 \%$ & - & - \\
& Overall Accuracy & - & - & - & $94.3 \%$ \\
\hline
\end{tabular}

\section{Discussion}

\subsection{Landscape Characteristics}

Because permafrost occurrence was so closely linked to elevated plateaus, the YKD study site is well suited to mapping permafrost based solely on high resolution elevation datasets (e.g., LiDAR). Other landscape features, such as river levees and ice-shoved ridges, can also create topography, but are easily identified based upon other geomorphic and geographic characteristics. This fundamental relationship between permafrost occurrence and surface elevation explains why high-resolution LiDAR performed well in mapping permafrost distribution. The average elevation of the plateaus reported by Jorgenson and Ely [24] - 2.84 $\mathrm{m}$ a.m.s.l.—is broadly consistent with the elevations we found for plateau margins ( $2.5 \mathrm{~m}$ a.m.s.l.). Theoretically, the average elevation of permafrost boundaries should be slightly lower than the average elevation of the plateaus. In this case, the maximum boundary elevation calculated (2.82 $\mathrm{m}$ a.m.s.l.) corresponds well with the mean elevation cited by Jorgenson and Ely [24].

While our field-based assessments of permafrost occurrence were made using a $1.25 \mathrm{~m}$ thaw probe, it is unlikely that permafrost was present at sample points that lacked frozen ground within $1.25 \mathrm{~m}$ of the surface during our fieldwork in mid-July. The mean depth of the bottom of frost $(86.6 \mathrm{~cm})$ also corroborates the unlikelihood of permafrost deeper than $1.25 \mathrm{~m}$. Previous studies $[5,24,29]$ measured thaw depths to $2.5 \mathrm{~m}$ in the Tutakoke River area, and consistently found no permafrost. It is likely that seasonal frost was encountered at the margins of the permafrost plateaus during fieldwork, but the mischaracterization of permafrost/non-permafrost arising from encountering seasonal frost was unlikely to occur in the center of plateaus because surface elevation and vegetation characteristics alone offer strong lines of evidence for permafrost occurrence. Furthermore, since thaw probing occurred at the same time, the relative thermal regimes among ecotypes is preserved, and many ecotypes did not contain permafrost.

The YKD climate, latitude, physiography, and vegetation cover make local surface elevation an excellent indicator of permafrost conditions. Other arctic deltas, such as the Lena Delta or the Mackenzie Delta, lie further north where colder climates result in continuous climate-driven permafrost distribution, even along the coast [28]. Other areas of sporadic to isolated permafrost found in Interior Alaska and across the Arctic have similar climates, but landscapes generally are not as flat and do not have interaction with coastal processes. The relationship between elevation, permafrost, and vegetation (i.e., permafrost creates topography, which supports distinct vegetation, which in turn protects permafrost) is by no means unique to the YKD, but makes it possible to identify permafrost with a higher degree of accuracy than is possible in landscapes with complex topography.

Permafrost identification on the YKD was highly accurate because of the unique topographical and vegetative characteristics of the plateaus. However, the relative abundance of permafrost on the delta is also an important factor to consider when mapping. As Panda et al. [36] note, the success of permafrost mapping is generally "higher when a larger part of the study area is underlain by permafrost: regardless of the technique used, the accuracy drops as the extent of permafrost becomes limited." Because the YKD mostly holds isolated to sporadic permafrost, precisely mapping permafrost 
extent is an inherently difficult task, but important given the vulnerability of the permafrost in the region to rising air temperatures and coastal flooding.

Where permafrost is present on the delta, it is found at relatively shallow depths. This is due to the highly insulative properties of vegetation and soils on the plateaus. For example, abundant mosses and lichens performing this service exemplify the concept of ecosystem-protected permafrost [28,37]. Vegetation cover, such as the Sphagnum peat and lichen present on the plateaus, provides an insulative layer that has low thermal conductivity in the summer, but higher thermal conductivity in the winter. This seasonal contrast in thermal conductivity allows for heat exchange from the ground in the winter, but prevents penetration of heat from the atmosphere in the summer [30]. Soil hydrology also plays an important role, since non-saturated soils provide better insulation than the wet soils found in the coastal meadows. On the flat delta, soil moisture is related to elevation, which can be seen in the mean elevation of each ecotype sampled during fieldwork (Figure 6). The analysis of thaw depths by ecotype shows that even subtle differences in soil moisture and vegetation type can lead to large differences in thaw depth. For example, the difference between the mean thaw depth in the LMGSM and the LWGSM ecotypes was $0.5 \mathrm{~m}$.

The direct and indirect impacts of saltwater flooding contribute to thermo-erosional processes and can initiate thermokarst $[24,25,38]$. Thus, the discovery that the shallowest average thaw depths occurred beneath storm wrack came as a surprise, since wrack lines tend to occur at plateau margins and were originally assumed to indicate areas at high risk of permafrost degradation. Though some thaw depths measurements under the WL group likely reflected seasonal frost rather than the permafrost table (in particular the $0.3 \mathrm{~m}$ thaw depth observed), the majority of sample sites under the WL had hard frozen soil, rather than the more easily penetrated soil indicative of seasonal frost with relatively high unfrozen water contents. The persistence of the permafrost may be due to the high albedo of the driftwood and herbaceous litter, which protects the permafrost by reflecting more solar radiation.

Not only is the permafrost shallow on the YKD, it is also likely thin. Areas of the YKD that currently have permafrost are relatively young compared to more stable permafrost on the North Slope, and in Interior Alaska and other colder, continental climatic zones across the pan-Arctic. The dynamic processes of the Yukon and Kuskokwim Rivers prevent permafrost formation on the landscape due to lateral movement of river channels and continuous deposition of sediment on active floodplains.

The mouth of the Yukon River flowed south into the Gulf of Alaska during the late Pliocene, and swung northward to its current location from glacial damming during the Pleistocene [39]. This movement, along with the movement in the Kuskokwim River's channel, indicates long-term existence of deltaic sediments in the broader delta region. The modern lobe of the Yukon River, however, is relatively young, and is estimated to have formed $\sim 2500$ years ago, constraining when permafrost in the region would have formed [40]. Jorgenson and Ely [24] suggest that this permafrost is transient in nature, and that formation may have started during the Little Ice Age (as late as 250-700 years ago), based on Dupré's [40] estimated permafrost thickness of 2-3 m, and Jorgenson and Ely's [24] estimate of $10 \mathrm{~m}$.

\subsection{LiDAR Mapping}

The majority of the error from using the $2.5 \mathrm{~m}$ a.m.s.l. threshold to map permafrost with LiDAR came from the relatively low $(80.3 \%)$ producer's accuracy of mapping permafrost. The much higher producer's accuracy of mapping areas without permafrost (98.9\%), shows the threshold did well in mapping areas without permafrost. Likewise, the high user's accuracies show that few areas without permafrost were mapped as permafrost, meaning that overall there were few errors of commission, and most of the error in the analysis came from omission of permafrost. This likely came from omitting smaller patches of permafrost on the inactive floodplain deposits (lower in elevation), such as the low-lying permafrost near Transect 7 (Figure 4), and lower elevations of the abandoned floodplain deposits. Since this is the type of permafrost that is most vulnerable to disappearing in the near future, 
an argument could be made to select a less conservative threshold (and decrease the user's accuracy) in order to capture patches of permafrost at lower elevations.

It should also be noted that the validation points were collected subjectively in the field (i.e., not systematically, stratified, etc.), so they may not accurately represent the distribution of permafrost on the landscape. This may have affected the estimates of mapping accuracy. However, the percent of the landscape described as permafrost from the validation points $(21.3 \%)$ is similar to other estimates from the literature [2,5], and not unrealistic of the landscape.

Looking at the LiDAR-derived permafrost probability map, the presence of permafrost is highly probable at higher elevations and improbable at low elevations, but the mid-elevations have high uncertainties. These areas of high uncertainty were mostly along the margins of the plateaus, where both elevation and predicted probability abruptly change. Thus, viewing the probability at a given location in a spatial context with nearby landscape characteristics could improve map quality and utility for long-term monitoring. For example, an area that shows an intermediate predicted probability of permafrost, but is located on an active floodplain, would likely not be permafrost in actuality. More likely, the higher predicted probability of permafrost in that area is driven by the elevation from a river levee, especially if it is close to river or tidal gut. Therefore, incorporating ancillary landscape maps into the analysis may improve mapping efforts. Errors of commission in areas known not to have permafrost could be reduced by limiting the LiDAR mapping by ecosection or ecodistrict (higher order hierarchical mapping delineations that Jorgenson [29] defines by geomorphology, soil texture, permafrost, and physiography). This type of contextual analysis was not explored here, but would be useful for future mapping efforts. High-resolution soil moisture datasets such as NASA's Airborne Microwave Observatory of Subcanopy and Subsurface (AirMOSS) would also be useful in distinguishing relatively moist permafrost plateaus from drier, sandy levee deposits or wet areas on the landscape that should lack permafrost.

\subsection{Spectral Integration}

The IKONOS imagery was incorporated into the analysis in an effort to exploit the contrast in vegetative characteristics between the permafrost plateaus and surrounding coastal meadows. However, the RT classifications explored did not increase mapping accuracy in comparison to the methods that used LiDAR data alone. In the case that used the same training as the logistic regression, the overall mapping accuracy actually decreased moderately (by $5.4 \%$ ). This was likely because the training data collected in the field were tailored to the plateau margins in the ambiguous elevations between 2.0 and $2.5 \mathrm{~m}$ a.m.s.l. on the inactive and abandoned floodplain deposits, and not with the intention of training a classification for the whole landscape. Thus, the second RT classification was run with a larger training dataset created from visual interpretation of the landscape. To reduce the ambiguity among land classes, the second RT classification also identified water features as a separate class.

The second RT classification performed better than the first RT classification both visually and statistically. Notably, the first RT classification erroneously identified transitions between floodplain deposits as having permafrost, as seen by the distinct north-south trending bands in the classified image (Figure 11i,ii), whereas the second RT classification did not. The second classification also created smoother and cleaner divisions than the first RT classification. However, the second RT classification still did not perform better than the LiDAR analysis alone. A possible explanation may be the spectral resolution of the IKONOS imagery. Though the IKONOS data have a high-spatial resolution, they have relatively low spectral resolution with only four bands. The nuances between the permafrost plateaus and the surrounding coastal meadows would be better distinguished from longer spectral wavelengths, which would identify vegetative differences better than the visible spectrum. Newer sensors such as WorldView 2 or 3 (eight-band spectral resolution) would likely perform better, but there are no data contemporary to the 2007 LiDAR that have both high spectral- and spatial-resolution. The integrated classifications may further be improved by larger forests or deeper trees, which would both increase processing time. Similarly, classification methods other than the RT classification may increase accuracy, but were not explored in this paper. 


\subsection{Paths for Regional Scale Mapping}

Though LiDAR data have been used in multi-temporal studies of permafrost degradation [8,18-20], we are unaware of previous efforts using LiDAR to map permafrost distribution explicitly. This analysis shows that, given the right permafrost conditions and landscape characteristics, LiDAR can be used to map permafrost extent with great precision. Frequently, ground ice in permafrost becomes the main driver of topography on an otherwise flat landscape, and it is precisely these landscapes in which this mapping technique works well.

Relatively flat landscapes with ice-rich permafrost can be mapped using elevation as a proxy for ice accretion and thus permafrost presence [41]. Possibilities include collapse-scar bogs, peat plateaus, wetland systems with palsas, and coastal plains in warmer parts of the Arctic, where accretion of ground ice creates identifiable topographic features. Other than the YKD, large parts of western Siberia, western Canada, northern Sweden, and Interior Alaska have the potential for this type of elevation-based mapping. This method is particularly useful in regions with sporadic to isolated permafrost, though its utility tends to decrease with increasing permafrost cover. As the Arctic warms, LiDAR may also become useful over other arctic deltas that currently have temperatures indicative of climate-driven permafrost, but may shift to ecosystem-driven or ecosystem-protected thermal regimes in the future [28].

However, there are limitations to using LiDAR to map permafrost extensively. First and foremost is finding areas suitable to elevation-based mapping (i.e., very flat landscapes). Here we have shown LiDAR works on the coastal plain of the YKD, but further inland, topography begins to influence permafrost mapping. Nevertheless, the YKD coastal plain accounts for approximately $14,600 \mathrm{~km}^{2}$, or $21.7 \%$ of the landscape as mapped by Jorgenson and Roth [5], making this technique applicable to a relatively large region. Secondly, the cost of LiDAR acquisition and processing may be prohibitive. Current rates for LiDAR flights are expensive, even assuming a fairly large area covered with low point density. Furthermore, processing time for DEM creation and geolocation are costly, both in time and data storage. These drawbacks are both a function of the scale of mapping, which is an important consideration when using LiDAR. The relatively small spatial extent of this analysis lent itself well to LiDAR, but expanding the scope to a regional scale is, unfortunately, unrealistic at present. However, current and planned LiDAR flights will soon expand landscape coverage in the region by ten times or more [42,43].

Repeat-pass LiDAR over areas that have already been sampled introduces another level of analysis. One advantage of LiDAR is the ability for 3-dimensional analysis. With repeat-pass LiDAR over the permafrost plateaus, a volumetric analysis of landscape change is possible, which has a myriad of applications. Tracking of thermokarst pit development, subsidence of plateaus, improved scaling of the potential carbon emissions from permafrost thaw, and redistribution of driftwood are a few of the possibilities that repeat-pass LiDAR offers in addition to tracking lateral movement of the permafrost plateau margins. Currently, there is increased interest in flying LiDAR on the YKD, especially along rivers and the coast where many communities face increased risk of flooding.

Other means of creating high-resolution elevation datasets also show promise for mapping permafrost in the region. Some techniques, such as high-resolution IfSAR (Interferometric-SAR) or space-borne laser altimeter systems still lack the spatial resolution necessary to provide adequate mapping, but high resolution Structure-from-Motion (SfM) processing may not share these problems. Since SfM relies on spectral datasets, collection costs are low compared to LiDAR campaigns. The fact that SfM processing only creates a digital surface model as opposed to a digital elevation model (roughly equivalent to the first return of a LiDAR collect, rather than the last return) is mitigated by the very low structure of the tundra vegetation canopy on the YKD. In other areas where shrub or tree cover demand elevation rather than surface models, SfM becomes a poor substitute for LiDAR, but the SfM technique has potential for many arctic tundra landscapes. The stereo-derived surface models from the recently released ArcticDEM still do not have the vertical resolution needed to map permafrost plateaus, which may be because the ArcticDEM creates a composite model from many 
scenes [44]. However, SfM or stereo-processing of a single image pair could result in better vertical resolution, which warrants further research.

\subsection{Broader Impacts}

This research, though implemented at a small scale, has both regional and global implications. As the Arctic warms, the stability of the permafrost on the YKD is vulnerable to rising air temperatures. At the same time, projected increases in storm frequency and intensity coupled with reduced sea-ice concentrations and snow cover will likely result in increased storm surge severity $[45,46]$. Because of the susceptibility of the permafrost to these disturbances, the permafrost plateaus are the vanguard of landscape change in the region. The permafrost in the region may likely be gone by the end of the century, and potentially much sooner $[10,24]$. In this way, geomorphic indicators on the plateaus reflect the larger scale changes occurring around the Arctic.

Degradation of these plateaus will have lasting impacts on the communities that rely on them. The permafrost plateaus are a major landscape feature that provide important ecosystem services to humans and wildlife alike. For instance, berries such as Rubus chamaemorus (cloudberry), R. arcticus (nagoonberry), and Empetrum nigrum (crowberry) are concentrated on the plateaus and are a staple in the native diet. The Rubus species, in particular, only grow on the permafrost plateaus, which has major implications for future subsistence gathering. Bird species of conservation concern, such as the Bristle-thighed Curlew (Numenius tahitiensis), also rely on berries and use the permafrost plateaus as crucial habitat [47]. Furthermore, many traditionally used sites and cultural resources are located on the permafrost plateaus. Burial sites, sod houses, and ancient villages were originally built on the plateaus because of the drier and higher ground. Today, many YKD communities are observing subsidence and disappearance of ancient village sites and other cultural resources [23]. Thus, mapping permafrost extent at high resolution is important to tracking degradation processes, and is important for local community planning, land management, and conservation of the highly productive wildlife habitats on the YKD.

Methods explored in this study lay the groundwork for region-wide mapping, and show that successful permafrost maps can be made using only high-resolution elevation datasets. The success of these methods is closely linked to the topography created by segregated ice in the soil on an otherwise flat terrain. These methods can only work given favorable permafrost conditions, and are thus not universal. However, these techniques are widely applicable to the flat YKD, and can easily be modified to map sporadic and discontinuous permafrost in other areas where permafrost development produces topographic breaks in otherwise flat landscapes.

\section{Conclusions}

This analysis explored a novel approach to mapping permafrost distribution on the YKD in western Alaska. We have shown that high-resolution LiDAR data, in tandem with field measurements, is successful in mapping permafrost distribution on the YKD. A simple elevation threshold was very successful in mapping permafrost extent based upon elevation boundaries of the LMGSM ecotype observed in the field. This method resulted in $94.9 \%$ total accuracy in mapping the landscape, and an $80.3 \%$ producer's accuracy in mapping permafrost. A probability map of permafrost extent was also created using a logistic regression based upon thaw-depth transects collected in the field. Integrating high spatial-resolution IKONOS data in RT classifications did not perform better than using the LiDAR alone, but were comparable (94.3\% overall accuracy) or only slightly worse (89.5\% overall accuracy). Despite these shortcomings, higher spectral-resolution data may increase model accuracy.

The LiDAR workflow is viable for mapping permafrost in the region, and has great promise for detecting even small-scale changes in the morphology of the plateaus through time with repeat coverage. Overall, this analysis demonstrates the viability of applying LiDAR and spectral datasets to mapping high-resolution permafrost distribution on the YKD, where otherwise conventional permafrost mapping techniques would be insufficient. Conclusions from this study will hopefully 
inform the permafrost mapping community about the viability of LiDAR for mapping permafrost in certain contexts, as well as provide baseline permafrost maps in an understudied region. These baseline maps are essential reference datasets for monitoring permafrost and future change on the YKD.

Acknowledgments: The authors would like to acknowledge funding from the NASA ABoVE grant \#NNH16CP09C for logistical and institutional support. This research was also supported in part by a UAF Global Change Student Research Grant Award (\#G00008751) with funds from the Cooperative Institute for Alaska Research. Partial publication funding came from the UAF Office of the Vice Chancellor for Research.

Author Contributions: M.T.J., G.V.F., M.A.W. and C.V.M. conceived and designed the experiments; M.T.J., G.V.F. and M.A.W. conducted the fieldwork; M.A.W. and M.J.M. processed the data; M.A.W., S.G.W. and G.V.F. analyzed the data, M.A.W., G.V.F. and C.V.M. wrote the paper.

Conflicts of Interest: The authors declare no conflict of interest.

\section{References}

1. Brown, J.; Ferrians, O., Jr.; Heginbottom, J.; Melnikov, E. Circum-Arctic Map of Permafrost and Ground-Ice Conditions; United States Geological Survey: Reston, VA, USA, 1997.

2. Jorgenson, M.T.; Yoshikawa, K.; Kanevskiy, M.; Shur, Y.; Romanovsky, V.; Marchenko, S.; Grosse, G.; Brown, J.; Jones, B. Permafrost characteristics of Alaska. In Proceedings of the Ninth International Conference on Permafrost, Fairbanks, AK, USA, 29 June-3 July 2008; pp. 121-122.

3. Cuff, D.; Goudie, A. The Oxford Companion to Global Change; Oxford University Press: Oxford, UK, 2009.

4. Hinzman, L.D.; Bettez, N.D.; Bolton, W.R.; Chapin, F.S.; Dyurgerov, M.B.; Fastie, C.L.; Griffith, B.; Hollister, R.D.; Hope, A.; Huntington, H.P. Evidence and implications of recent climate change in northern Alaska and other Arctic regions. Clim. Chang. 2005, 72, 251-298. [CrossRef]

5. Jorgenson, M.T.; Roth, J.E. Landscape Classification and Mapping for the Yukon-Kuskokwim Delta: Final Report Prepared for: U.S. Fish and Wildlife Service; ABR, Inc.-Environmental Research \& Service: Fairbanks, AK, USA, 2010; p. 24.

6. Romanovsky, V.E.; Smith, S.L.; Christiansen, H.H. Permafrost thermal state in the polar northern hemisphere during the international polar year 2007-2009: A synthesis. Permafr. Periglac. Process. 2010, 21, 106-116. [CrossRef]

7. Schuur, E.; McGuire, A.; Schädel, C.; Grosse, G.; Harden, J.; Hayes, D.; Hugelius, G.; Koven, C.; Kuhry, P.; Lawrence, D. Climate change and the permafrost carbon feedback. Nature 2015, 520, 171-179. [CrossRef] [PubMed]

8. Liljedahl, A.K.; Boike, J.; Daanen, R.P.; Fedorov, A.N.; Frost, G.V.; Grosse, G.; Hinzman, L.D.; Iijma, Y.; Jorgenson, J.C.; Matveyeva, N. Pan-Arctic ice-wedge degradation in warming permafrost and its influence on tundra hydrology. Nat. Geosci. 2016, 9, 312-318. [CrossRef]

9. Riseborough, D.; Shiklomanov, N.; Etzelmüller, B.; Gruber, S.; Marchenko, S. Recent advances in permafrost modelling. Permafr. Periglac. Process. 2008, 19, 137-156. [CrossRef]

10. Pastick, N.J.; Jorgenson, M.T.; Wylie, B.K.; Nield, S.J.; Johnson, K.D.; Finley, A.O. Distribution of near-surface permafrost in Alaska: Estimates of present and future conditions. Remote Sens. Environ. 2015, 168, 301-315. [CrossRef]

11. Jafarov, E.E.; Marchenko, S.S.; Romanovsky, V. Numerical modeling of permafrost dynamics in Alaska using a high spatial resolution dataset. Cryosphere 2012, 6, 613-624. [CrossRef]

12. Zhang, Y.; Chen, W.; Riseborough, D.W. Disequilibrium response of permafrost thaw to climate warming in Canada over 1850-2100. Geophys. Res. Lett. 2008, 35. [CrossRef]

13. Slater, A.G.; Lawrence, D.M. Diagnosing present and future permafrost from climate models. J. Clim. 2013, 26, 5608-5623. [CrossRef]

14. Heginbottom, J.A. Permafrost mapping: A review. Prog. Phys. Geogr. 2002, 26, 623-642. [CrossRef]

15. Jorgenson, M.T.; Grosse, G. Remote sensing of landscape change in permafrost regions. Permafr. Periglac. Process. 2016, 27, 324-338. [CrossRef]

16. Gogineni, P.; Romanovsky, V.; Cherry, J.; Duguay, C.; Goetz, S.; Jorgenson, M.; Moghaddami, M. Opportunities to Use Remote Sensing in Understanding Permafrost and Related Ecological Characteristics: Report of a Workshop; National Academies Press: Washington, DC, USA, 2014; p. 97. 
17. Westermann, S.; Østby, T.; Gisnås, K.; Schuler, T.; Etzelmüller, B. A ground temperature map of the North Atlantic permafrost region based on remote sensing and reanalysis data. Cryosphere 2015, 9, 1303-1319. [CrossRef]

18. Jones, B.M.; Grosse, G.; Arp, C.D.; Miller, E.; Liu, L.; Hayes, D.J.; Larsen, C.F. Recent Arctic tundra fire initiates widespread thermokarst development. Sci. Rep. 2015, 5, 15865. [CrossRef] [PubMed]

19. Jones, B.M.; Stoker, J.M.; Gibbs, A.E.; Grosse, G.; Romanovsky, V.E.; Douglas, T.A.; Kinsman, N.E.; Richmond, B.M. Quantifying landscape change in an Arctic coastal lowland using repeat airborne LiDAR. Environ. Res. Lett. 2013, 8, 045025. [CrossRef]

20. Paine, J.G.; Andrews, J.R.; Saylam, K.; Tremblay, T.A.; Averett, A.R.; Caudle, T.L.; Meyer, T.; Young, M.H. Airborne LiDAR on the Alaskan North Slope: Wetlands mapping, lake volumes, and permafrost features. Lead. Edge 2013, 32, 798-805. [CrossRef]

21. Thorsteinson, L.K.; Becker, P.R.; Hale, D.A. The Yukon Delta: A Synthesis of Information; OCS Study, MMs 89-0081; National Oceanic Atmospheric Administration: Anchorage, AK, USA, 1989; p. 89.

22. Klein, D.R. Waterfowl in the economy of the eskimos on the Yukon-Kuskokwim Delta, Alaska. Arctic 1966, 19, 319-336. [CrossRef]

23. Fienup-Riordan, A.; Rearden, A. Ellavut/Our Yup'ik World and Weather: Continuity and Change on the Bering Sea Coast; University of Washington Press: Seattle, WA, USA, 2013.

24. Jorgenson, T.; Ely, C. Topography and flooding of coastal ecosystems on the Yukon-Kuskokwim Delta, Alaska: Implications for sea-level rise. J. Coast. Res. 2001, 17, 124-136.

25. Terenzi, J.; Jorgenson, M.T.; Ely, C.R.; Giguère, N. Storm-surge flooding on the Yukon-Kuskokwim Delta, Alaska. Arctic 2014, 67, 360-374. [CrossRef]

26. Péwé, R.; Brown, T. Distribution of permafrost in North America and its relationship to the environment: A review, 1963-1973. In Permafrost: North American Contribution [to The] Second International Conference; National Academies: Washington, DC, USA, 1973; p. 71.

27. NOAA/NCDC. Daily Temperature Record for Bethel Airport, AK US 1923-2016; ghcnd:Usw00026615; National Oceanic and Atmospheric Administration (NOAA): Silver Spring, MD, USA, 2017.

28. Shur, Y.; Jorgenson, M. Patterns of permafrost formation and degradation in relation to climate and ecosystems. Permafr. Periglac. Process. 2007, 18, 7-19. [CrossRef]

29. Jorgenson, M.T. Hierarchical organization of ecosystems at multiple spatial scales on the Yukon-Kuskokwim Delta, Alaska, USA. Arct. Antarct. Alp. Res. 2000, 32, 221-239. [CrossRef]

30. Tyrtikov, A.P. Perennially frozen ground and vegetation. In Principles of Geocryology (Permafrost Studies), Part I, General Geocryology, Chapter XII; Academy of Sciences of the U.S.S.R.: Moscow, Russia, 1964.

31. Dunnett, C.W. Pairwise multiple comparisons in the homogeneous variance, unequal sample size case. J. Am. Stat. Assoc. 1980, 75, 789-795. [CrossRef]

32. Airborne Imaging. Final LiDAR processing \& vertical accuracy report: Prepared for the U.S. Fish and Wildlife Service. In LiDAR Imagery \& DEM Model for Yukon Delta National Wildlife Refuge-Near Angyaravak Bay, Alaska; Airborne Imaging: Calgary, AB, Canada, 2011; p. 28.

33. Lillesand, T.; Kiefer, R.W.; Chipman, J. Remote Sensing and Image Interpretation; John Wiley \& Sons: Hoboken, NJ, USA, 2014.

34. ESRI. Arcgis Desktop: Release 10.4; Enivronmental Systems Research Institute: Redlands, CA, USA, 2015.

35. Breiman, L. Random forests. Mach. Learn. 2001, 45, 5-32. [CrossRef]

36. Panda, S.K.; Prakash, A.; Solie, D.N.; Romanovsky, V.E.; Jorgenson, M.T. Remote sensing and field-based mapping of permafrost distribution along the Alaska highway corridor, Interior Alaska. Permafr. Periglac. Process. 2010, 21, 271-281. [CrossRef]

37. Blok, D.; Heijmans, M.; Schaepman-Strub, G.; van Ruijven, J.; Parmentier, F.; Maximov, T.; Berendse, F. The cooling capacity of mosses: Controls on water and energy fluxes in a Siberian tundra site. Ecosystems 2011, 14, 1055-1065. [CrossRef]

38. Kokelj, S.; Jorgenson, M. Advances in thermokarst research. Permafr. Periglac. Process. 2013, 24, 108-119. [CrossRef]

39. Duk-Rodkin, A.; Barendregt, R.; White, J.; Singhroy, V. Geologic evolution of the Yukon River: Implications for placer gold. Quat. Int. 2001, 82, 5-31. [CrossRef]

40. Dupré, W.R. Yukon Delta Coastal Processes Study; Department of Geology, University of Houston: Houston, TX, USA, 1980. 
41. Douglas, T.A.; Jorgenson, M.T.; Brown, D.R.; Campbell, S.W.; Hiemstra, C.A.; Saari, S.P.; Bjella, K.; Liljedahl, A.K. Degrading permafrost mapped with electrical resistivity tomography, airborne imagery and LiDAR, and seasonal thaw measurements. Geophysics 2015, 81, WA71-WA85. [CrossRef]

42. USGS-3DEP. U.S. Geological Survey Broad Agency Announcement for 3D Elevation Program (3DEP) g15ps00558; United States Geological Survey: Reston, VA, USA, 2015; pp. 1-20.

43. Murphy, K. Agency Priorities for 3DEP Lidar Collection-Yukon-Kuskokwim Delta. Western Alaska Landscape Conservation Cooperative (WALCC). 2016. Available online: https:/ / eros.usgs.gov/doi-remotesensing-activities / 2016/lidar-collection-outer-coastal-regions-yukon-and-kuskokwim-river-deltas (accessed on 5 February 2018).

44. Polar Geospatial Center. ArcticDEM; Center, P.G., Ed.; University of Minnesota: Minneapolis, MN, USA, 2017.

45. Bhatt, U.S.; Walker, D.A.; Walsh, J.E.; Carmack, E.C.; Frey, K.E.; Meier, W.N.; Moore, S.E.; Parmentier, F.-J.W.; Post, E.; Romanovsky, V.E.; et al. Implications of Arctic sea ice decline for the earth system. Annu. Rev. Environ. Res. 2014, 39, 57-89. [CrossRef]

46. Macander, M.; Swingley, C.; Parr, C.; Sturm, M.; Selkowitz, D.; Larsen, C. Snow Depth and Snow Persistence Patterns in the Arctic from Analysis of the Entire Landsat Archive; AGU Fall Meeting Abstracts: San Francisco, CA, USA, 2016.

47. Marks, J.; Tibbitts, T.; Gill, R.; McCaffery, B. Bristle-thighed curlew (Numenius tahitiensis). Birds N. Am. 2002, 705, 1-36. [CrossRef]

(C) 2018 by the authors. Licensee MDPI, Basel, Switzerland. This article is an open access article distributed under the terms and conditions of the Creative Commons Attribution (CC BY) license (http:/ / creativecommons.org/licenses/by/4.0/). 